\title{
BIM-Integrated Simulation of Construction Operations for Lean Production Management
}

\author{
SooWon $\mathrm{CHANG}^{1}$, JeongWook $\mathrm{SON}^{2 *}$, WoonSeong $\mathrm{JEONG}^{3}$ and June-Seong $\mathrm{YI}^{4}$ \\ ${ }^{1}$ Graduate Student, Department of Architectural Engineering, Ewha Womans University \\ ${ }^{2}$ Assistant Professor, Department of Architectural Engineering, Ewha Womans University \\ ${ }^{3}$ Postdoc, Department of Architectural Engineering, Ewha Womans University \\ ${ }^{4}$ Associate Professor, Department of Architectural Engineering, Ewha Womans University \\ *Corresponding author's e-mail: jwson@ewha.ac.kr
}

\begin{abstract}
As construction projects become larger and more complex, traditional construction planning and control practice which relies on historical data and heuristic adjustment can no longer produce a plan that incorporates all the managerial details such as productivity dynamics. In addition, the plan, more often than not, does not synchronize with the procurement schedule; as a result, the whole supply chain has failed to accomplish expected level of efficiency. In these regards, this paper presents a simulation framework that can not only predict productivity dynamics by considering factors affecting on productivity at the operational level, but also automatically generate a procurement plan harmonizing with the simulation results for reliable production management. We developed APIs for the framework 1) enabling a BIM model to produce input data for the construction operation simulation; 2) composing construction simulation in operational level; 3 ) facilitating the productivity prediction by providing BIMintegrated construction simulation models. The simulation framework had tested with structural steel erection cases. The results show that we can expect significant improvement of efficiency along supply chain including optimized resource allocation, schedule reliability increase, storage cost saving, and material loss reduction.
\end{abstract}

\section{KEYWORDS}

Computer Simulation, BIM, Supply Chain, Just-In-Time, Productivity

\section{INTRODUCTION}

As construction projects become larger and more complex, traditional construction planning and control practice can no longer produce a plan that incorporates all the project details such as design complexity, work difficulty, learning curve, and coordination process. While daily construction production and resource plan has been established based on historical data and managers' heuristic adjustment, actual productivity are subject to be deviated from the original plan. There are reasons why the productivity is abstruse to be predicted. First, construction projects have unique characteristics: construction projects differs in location, design, level of labor skill, and project team composition. The new setup and environment of the project adds more uncertainty to the planning process, so that make it difficult to predict performance from data collected from past cases. Second, construction productivity is affected by operational and managerial factors. A variety of factors which could have influence on construction productivity have been identified. However, current planning practice does not consider operational and managerial details.

In this regard, this paper introduces our continuing research endeavor to develop a simulation framework that can not only predict reliable productivity dynamics by considering factors affecting on productivity at the operational level, but also automatically generate a procurement 
plan harmonizing with the simulation results for reliable production management. To accomplish this objective, Building Information Model (BIM) is integrated with construction operation simulations. Simulations are fed data of the building elements, which is already generated in the BIM and will be input of the simulations. The developed BIM-integrated simulation perform construction operations in a virtual world and generate forecasted productivity dynamics.

\section{LITERATURE REVIEW}

\section{Simulation in construction}

Though computer simulation has been introduced in construction field to improve estimating, planning, and control (AbouRizk \& Mohamed, 2002), it has not been widely used in the industry due to low generality and difficulties of development. In this respect, it seems that making simulation development process convenient and realistic is particularly important to promote the use of computer simulation for construction management.

\section{BIM applications}

The rapid progress of BIM technology made building performance evaluation quicker and easier. Building performance analysis tools such as energy efficiency (Azhar \& Brown, 2009) and structural analysis extract required data from BIM and reuse them to produce outcomes. However, in construction management domain, they have used BIM data only for simple purposes; for example, automated generation of schedules (Mikulakova, König, Tauscher, \& Beucke, 2010) and quantity-takeoff. Because reusing BIM data can significantly reduce time and effort for reproduction of building data, it could be a breakthrough to improve efficiency and reliability of construction management and performance analysis.

\section{Lean construction}

The primary goal of lean production is to avoid waste of time, money, equipment, etc; everything is focused on productivity improvement and cost reduction (Melles, 1997). One of the most important instruments of lean production is Just-in-time (JIT) delivery. It reduces the stocks of materials through the concept that new subassemblies are made only immediately before they are actually needed (Melles, 1997), so that the implementation of JIT needs reliable production (Melles, 1997).

\section{PRODUCTIVTY DYNAMICS}

The fluctuation between a plan and execution makes waste of time and money (Figure 1). According to the Parade game theory in construction (Tommelein, Riley, \& Howell, 1999), the more variability between supply and demand, the much more inventory buffers in lower providers' storage. High level of variability decreases the efficiency of the whole supply chain by adding waste of time and money from unnecessary inventory management. Holding inventory of each participants in supply chain compel end-buyer to undertake an unknown risk because some suppliers shift their risk to buyer behind the scenes.

For minimizing the waste of the whole construction process, it is important to precisely predict productivity. Reliable productivity dynamics prediction allows managers to make adequate resource plan.Incorrect productivity prediction also can add inefficiency. Unexpected deviation between the original plan and observed progress makes managers input excessive resources when observed progress is worse than the original plan (input insufficient resources when observed progress is better). This fluctuation results in additional cost and time and therefore the whole supply chain has failed to accomplish expected level of efficiency. 


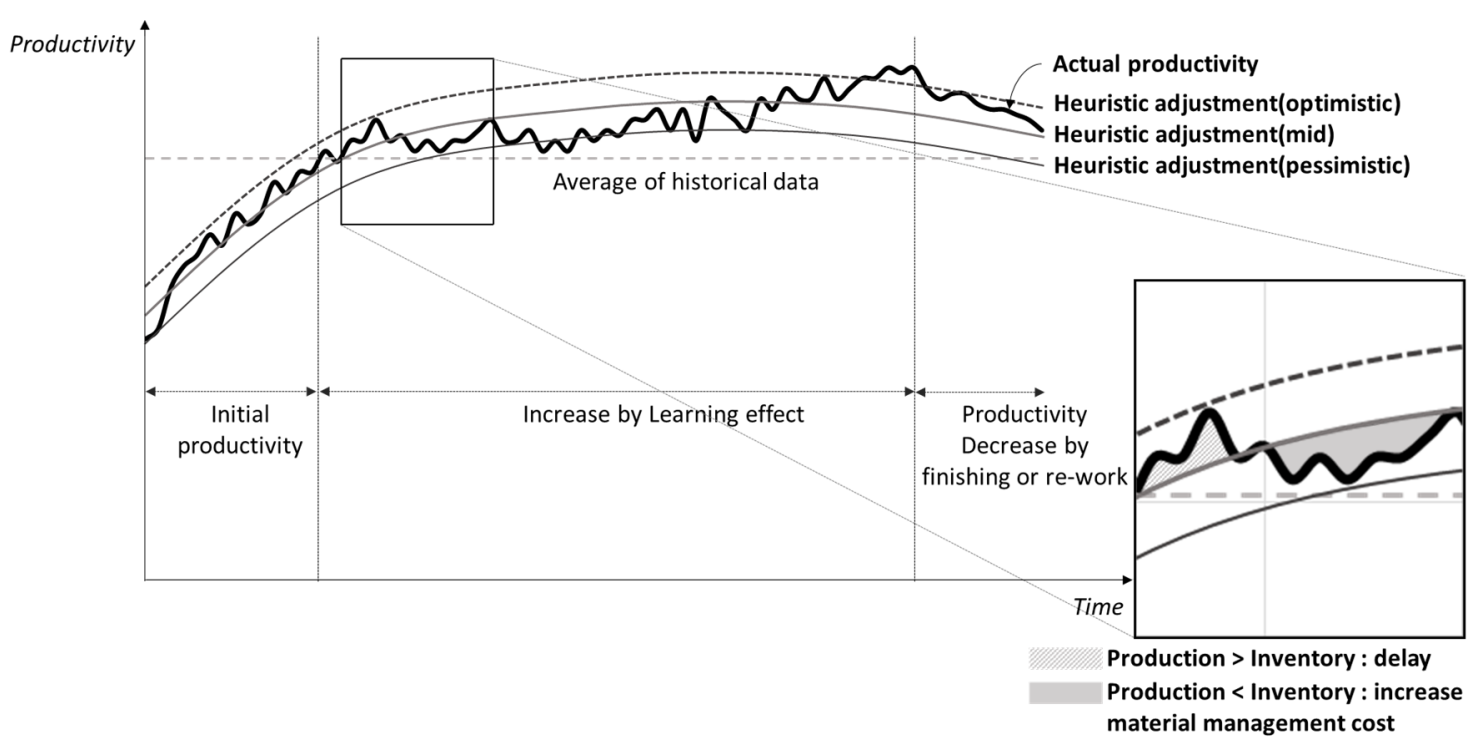

Figure 1. Productivity dynamics

\section{BIM-SIM INTEGRATION FOR CONSTRUCTION MANAGEMENT}

Authors have developed a simulation framework that can not only predict productivity dynamics by considering factors affecting on productivity at the operational level, but also automatically generate a procurement plan harmonizing with the simulation results for reliable production management. The simulation model was integrated with BIM: it extracts necessary input from a pre-built BIM model such as geometry and construction location and output expected work productivity as a result of running the simulation incorporating all operational and managerial details to estimate work productivity (Figure 2).

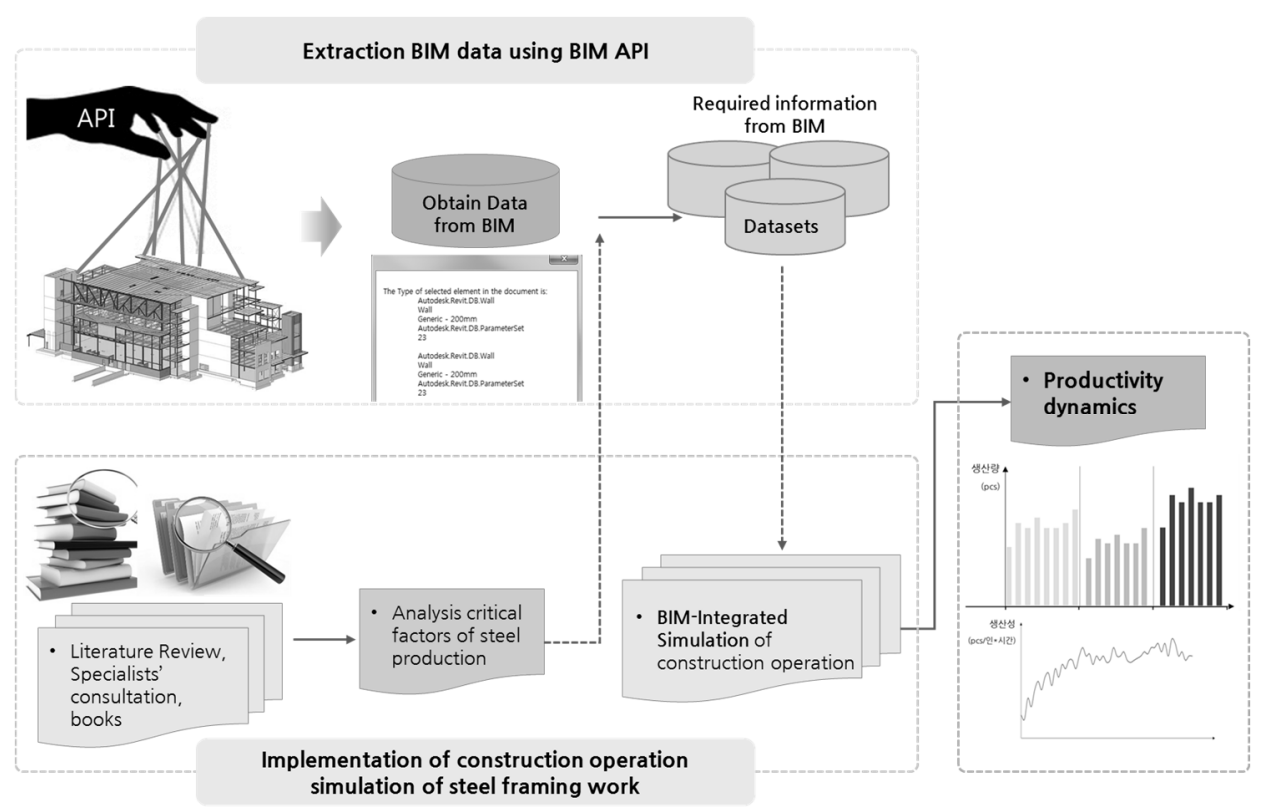

Figure 2. BIM-integrated simulation framework

Commands to interchange data between the simulation and a BIM model were developed. We used Autodesk Revit which provides an Application Programming Interface (API) to utilize data. The following procedures are needed for extracting BIM data required (Figure 3):

- Preparing a pre-built BIM model

- Building a code which can extract data in BIM 
- Constructing Dataset sorted for simulation

- Translating dataset into input data for utilizing simulation

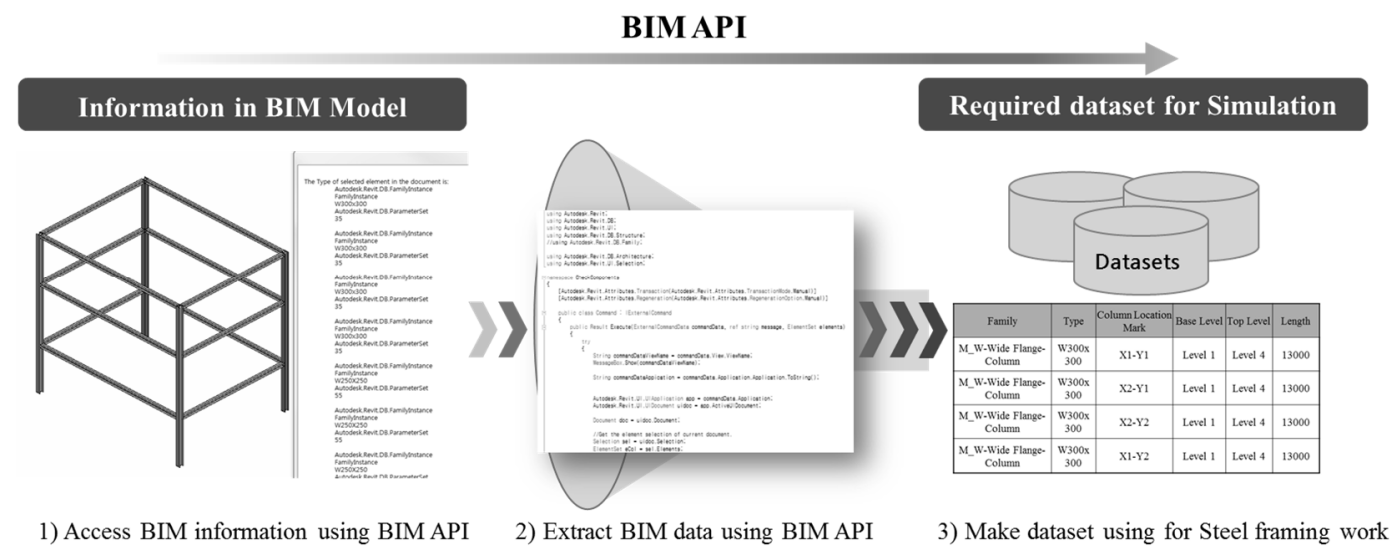

Figure 3. Command implementation using Autodesk Revit APIs

Construction operation simulations were developed. To build reliable simulation, authors scrutinize construction processes thoroughly by reading references and expert interview. A conceptual model as a drawing to develop simulations was developed and factors affecting on work productivity were listed. Based on the collected information, construction operation simulations were developed using Anylogic software. The following tasks are required for developing and conducting computer simulation (Figure 4):

- Organizing work procedures of construction operation

- Finding factors affecting on work productivity

- Developing a simulation

- Extracting data regarding a building from BIM

- Implementing computer simulations

- Run the computer simulations and collect results

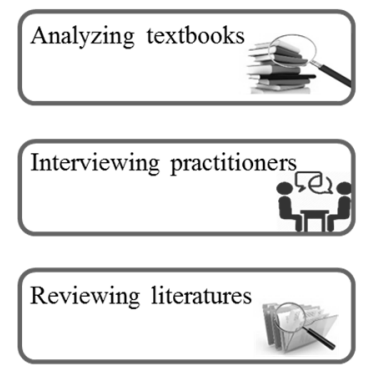

1) Study about steel framing work

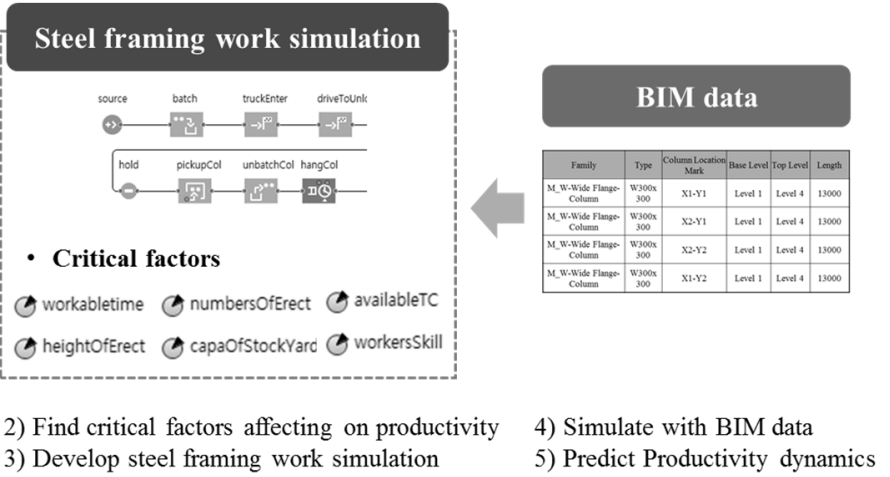

3) Develop steel framing work simulation

5) Predict Productivity dynamics

Figure 4. Simulation development process

\section{CASE: STEEL FRAMING WORK}

The developed simulation framework was applied to steel framing work. Steel framing work is chosen as a case because it is one of the most critical process which affects on the total project cost and work productivity could vary depending on the work conditions. Discrete Event Simulation approach was adopted to create steel framing work simulation. In order to developy BIM-integrated steel framing work simulation, we followed the process below:

1) Preparing a BIM model and producing input data: 
We created a steel-structured BIM model to demonstrate our framework. The BIM model facilitates preparing the required information for the construction simulation model including the number of columns and beams and the size and type of each column and beam. After creating the BIM model, the developed commands using APIs enabled the required information to be retrieved from the BIM model automatically. The commands translates the extracted data into input data for resource information in the simulation model. Figure 5 shows the required information retrieval process from the BIM model and the data translation between the BIM model and the simulation model.

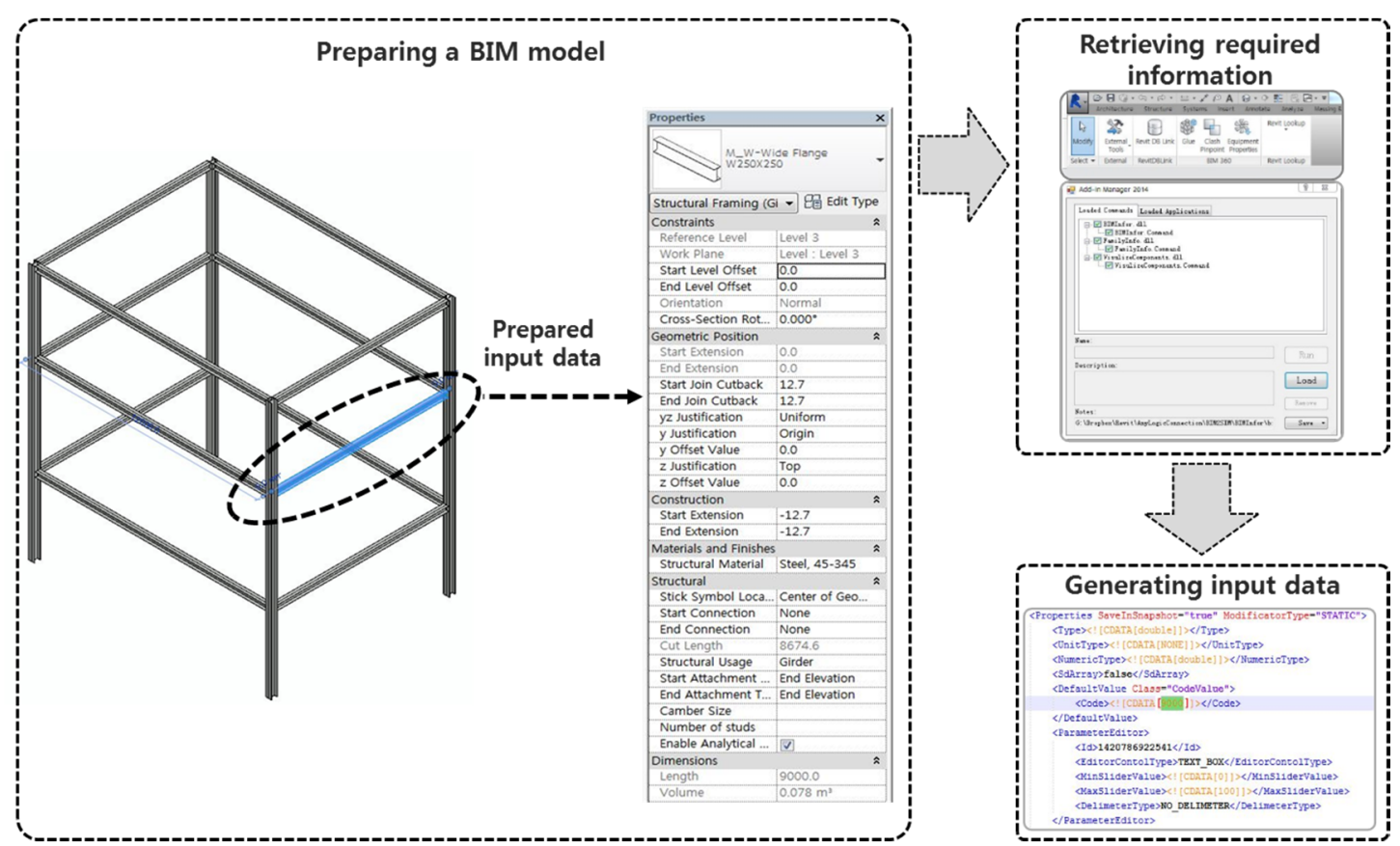

Figure 5. Data retrieval process from a BIM model and input data preparation process

2) Developing construction operation simulations:

In accordance with analyzing references and expert interview, we summarized steel framing work process in operational level, and then we express these work process as a simulation model using Anylogic software (Figure 6). In addition, the number for workable days, height in which workers work, the number of materials, stockyard space, utilization of tower crane, and skill of workers were identified as critical factors determining work productivity in steel framing work. In order to incorporate those factors in the simulation, we use schedule and parameters in Anylogic software.

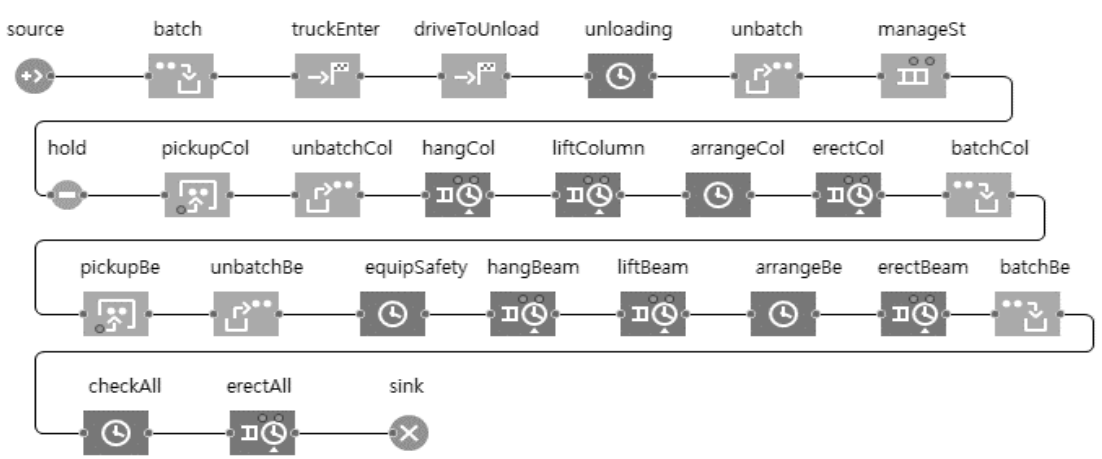

Figure 6. Steel framing work simulation model in Anylogic

3) Running the simulation: 
Running the simulation produces work productivity for each building elements - steel columns and beams. Productivity is defined as the ratio of output to inputs used in the production process that is the number of steels erected per a unit time or resource. The inputs of steel framing work are resources, such as laborers, forklift, and tower-crane. When number of column is 4 and number of beam is 12 according to the data from BIM, and when capacity of stockyard is 20 and number of materials which Tower crane can move is 1 , the productivity of steel framing work is the following chart in Figure 7 9.

\section{RESULTS AND DISCUSSION}

The simulation results shows that productivity decreased near the junctions the point of ending of column erection or ending of beam erection. This might be because alienation of work occurs at that point. Furthermore, in Figure 8, there are four productivity peaks. Erection work is the most productive in second height, and the productivity is decreased as increasing the height of erection work. Compared Figure 7 and 8 , we can figure out the productivity of erecting beam is greater than that of erecting column. This is might be because columns, which are erected before erecting beam, would be able to buttress beams. Moreover, we can check that the methodology using BIM-integrated simulation can predict more accurate productivity dynamic rather than traditional method using historical data and heuristic adjustments. Although this simulation does not reflect the real construction situation as it is, the productivity dynamics, which is shown in Figure 9, are quite reliable because the graphs show us the results that can usually happen in real situation. This results are not perfect yet, but quite reliable.

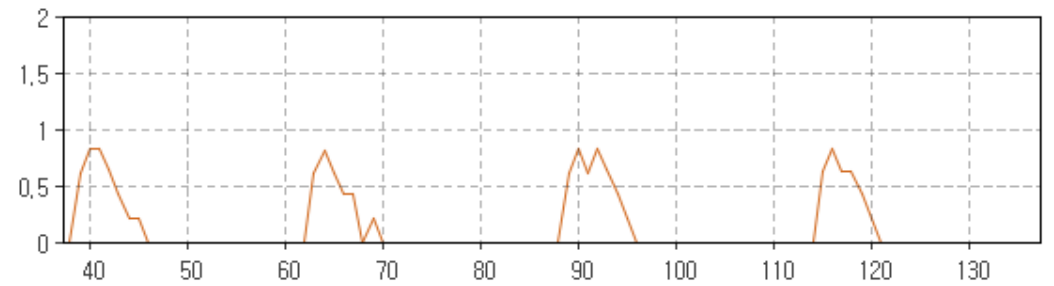

Figure 7. Productivity of Column erection (units/hour*worker*equipment)

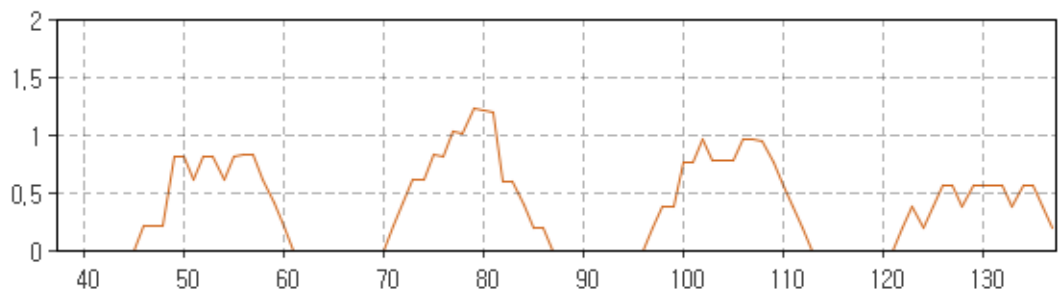

Figure 8. Productivity of Beam erection (units/ hour*worker*equipment)

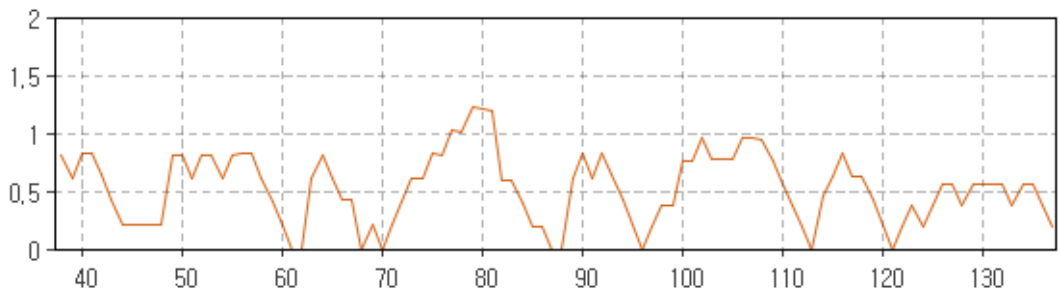

Figure 9. Total Productivity of steel framing work (units/ hour*worker*equipment)

\section{CONCLUSIONS}

In this research, we presents the methodology predicting reliable productivity dynamics in construction operation level. Additionally, we can check that BIM-integrated simulation 
framework is plausible methodology to predict productivity dynamic in construction field. In this research, it is particularly important to use BIM data for planning construction management. We come to know further possibility usage of BIM in construction management field. On the other hand, there are some limitations of this research. This framework is only evaluated about a simple steel structure model, and this model does not exist in real. In addition, to check and visualize the results of simulation faster, we reduced the simulation time by second time level. At this procedure, the observation error might be generated. In the future, authors will evaluate the value of each simulation steps, and the simulation will be more reflected the real construction situation. Additionally, authors plan to study this framework further in order to support construction managers' decision-making. To support decision-making for construction managers, we need to suggest more intuitive results.

\section{ACKNOWLEDGEMENTS}

This research was supported by Basic Science Research Program through the National Research Foundation of Korea(NRF) funded by the Ministry of Science, ICT and Future Planning (No. NRF-2013R1A2A2A04014772 and No. NRF-2013R1A1A1010562)

\section{REFERENCES}

AbouRizk, S., \& Mohamed, Y. (2002). "Optimal construction project planning." Paper presented at the Simulation Conference, 2002. Proceedings of the Winter.

Mikulakova, E., König, M., Tauscher, E., \& Beucke, K. (2010). "Knowledge-based schedule generation and evaluation." Advanced Engineering Informatics, 24(4), 389-403.

Tommelein, I. D., Riley, D. R., \& Howell, G. A. (1999). "Parade game: Impact of work flow variability on trade performance." Journal of Construction Engineering and Management, 125(5), 304-310. 